Article

\title{
Analysis of Doubly Fed Induction Generators Participating in Continuous Frequency Regulation with Different Wind Speeds Considering Regulation Power Constraints
}

\author{
Tingting Cai ${ }^{1,2, *}$, Sutong Liu ${ }^{2}$, Gangui Yan ${ }^{2}$ and Hongbo Liu ${ }^{2}$ \\ 1 School of electrical and Electronic Engineering, North China Electric Power University, Beijing 102206, China \\ 2 Key Laboratory of Modern Power System Simulation and Control \& Renewable Energy Technology, \\ Ministry of Education (Northeast Electric Power University), Jilin 132012, China; \\ 2201700145@neepu.edu.cn (S.L.); yangg@neepu.edu.cn (G.Y.); liuhb@neepu.edu.cn (H.L.) \\ * Correspondence: 20102182@neepu.edu.cn; Tel.: +86-0432-64806691
}

Received: 17 January 2019; Accepted: 13 February 2019; Published: 16 February 2019

check for updates

\begin{abstract}
Wind turbines (WTs) participate in frequency regulation, which is one of the means to solve the problem of inadequate regulation capacity in power systems with a high proportion of renewable energy. The doubly fed induction generator (DFIG) can reserve part of power to achieve bidirectional regulation capability through rotor over-speed and increasing pitch angle. In this paper, it is pointed out that the available bidirectional regulation power of the WT is constrained by the maximum regulation power under the rotor speed regulation. The regulation power constraints under the pitch regulation considering the time scale are calculated. The adjustment coefficient of WT participating in frequency regulation is designed. Considering the regulation power constraints, the frequency difference interval in which the WT can provide the regulation power according to the adjustment coefficient is analyzed. The rotor speed and pitch coordinated control strategy of DFIG with different wind speeds is designed. Based on 24-hour measured data from a wind farm, the power constraints and their effects of WTs in the wind farm participating in frequency regulation are verified by simulation. The regulation power of the wind farm, frequency quality, and wind power utilization under the different control strategies are analyzed. The results show that the effects of bidirectional power constraints must be taken into account when evaluating the effectiveness of WTs in continuous frequency regulation.
\end{abstract}

Keywords: doubly fed induction generator (DFIG); frequency regulation; regulation power constraints; adjustment coefficient; speed and pitch coordinated control

\section{Introduction}

The global wind power market remained above $50 \mathrm{GW}$ in 2017. Total installations in 2017 were $52,492 \mathrm{MW}$, bringing the global total to 539,123 MW. The annual market was in fact down $3.8 \%$ on from 2016 's 54,642 MW, while the cumulative total was up 11\% over 2016's year-end total of 487,279 MW. Today we have commercial wind operations in more than 90 countries around the world, nine of them, including China, the US, Germany, India, Spain, the UK, France, Brazil and Canada, with more than 10,000 MW. Thirty countries across Europe, Asia, North America, Latin America and Africa have more than 1000 MW [1].

Wind power generation is one of the most mature and large-scale developments in new energy generation technologies. However, due to the randomness and volatility of wind power, and lack of the frequency regulation capability, the large-scale high penetration wind power integration is adverse 
to the frequency stability of the power system. For this reason, the world's major developed wind power countries and regions have standardized the frequency regulation capability of wind power by the grid code and make explicit requirements [2,3].

At present, DFIG is the trunk stream model of a large-scale wind farm [4]. In the traditional control mode, the DFIG operates at the maximum power point tracking (MPPT) mode, with only downward regulation capability (regulating the positive frequency difference), and cannot regulate in two directions. At present, there are three control methods for DFIGs participating in primary frequency regulation, including virtual inertia control, rotor speed control and pitch control. References [5-7] studied the virtual inertial control of the WT and realize the virtual inertial response of the system. It is verified that the virtual inertial control reduces the frequency fluctuation and improves the system frequency transient stability. References [8,9] pointed out that the WT can only participate in frequency regulation for a short time by the virtual inertia control, because there is no reserved power in the WT, so it is impossible to support system frequency in a long term. References [10-13] verified that the WT can realize the system primary frequency regulation under the rotor speed control strategy, so the problem that the WT can only participate in the short term frequency regulation and easily cause secondary frequency drops under the traditional inertial control is avoided. References [14-17] studied the frequency control method of the WT based on pitch control, and verified the effectiveness of the method.

The virtual inertial control uses the rotor's kinetic energy to provide an inertial response, which has the advantage of quick response to any system frequency changes. However, after the inertial response, the wind power will be lower than the initial value as the speed decreases, which increases the additional demand for regulation power [18]. For this reason, this paper does not consider the virtual inertia control frequency regulation method. Rotor speed control is based on the control technology of the converter. The control speed is faster than pitch control, but it is limited by the rated rotor speed, which is applicable to the below-rated wind speeds $[19,20]$. The pitch control is applicable to a wide range of wind speeds, but the pitch actuator is a mechanical component, which frequent use will aggravate the mechanical losses, increase overhaul costs and reduce the service life of the WT [21-23]. Therefore, based on the principle of giving full play to the role of rotor speed regulation and minimizing the frequency and amplitude of pitch angle action, a rotor speed and pitch coordinated control strategy with different wind speeds is designed in this paper.

Most related studies by domestic and foreign scholars are on the dynamic response of the WT participating in frequency regulation at a certain wind speed, when a single frequency disturbance occurs. This verifies the feasibility of the WT participating in the system frequency regulation. However, the system frequency regulation is a long term dynamic process, so it is necessary to investigate the capacity and effects of the WT participating in frequency regulation under continuous frequency disturbance conditions. Therefore, this paper studies the bidirectional power constraints under the rotor speed frequency regulation, and the time scale constraints under the pitch frequency regulation of the WT. The effects of regulation power constraints on the WT participating in frequency regulation during the long term frequency regulation process is pointed out. The rotor speed and pitch coordinated control strategy with different wind speeds is proposed. Based on 24-hour measured data of a wind farm, the bidirectional regulation power constraints and its effects are simulated and analyzed in the continuous frequency disturbances process. The research of this paper provided a theoretical basis for WTs participating in the long term continuous frequency regulation, especially for the primary frequency regulation research of high penetration wind power system.

\section{Mathematical Model of DFIG}

The expression of the WT mechanical power $P_{\mathrm{m}}$ is as follows [24,25]:

$$
P_{\mathrm{m}}=\frac{1}{2} \rho S v^{3} C_{\mathrm{p}}(\lambda, \beta)
$$


where $\rho$ is the air density; $S$ is the rotor sweep area; $v$ is the wind speed and $C_{\mathrm{P}}$ is the wind energy utilization coefficient.

Under a certain wind speed, the mechanical power of the WT is determined by $C_{\mathrm{P}}$, which is a function of the tip speed ratio $\lambda$ and the pitch angle $\beta$. It is approximated by the following equation [26]:

$$
\left\{\begin{array}{l}
C_{\mathrm{p}}=c_{1}\left(\frac{c_{2}}{\lambda_{i}}-c_{3} \beta-c_{4}\right) e^{-\frac{c_{5}}{\lambda_{i}}}+c_{6} \lambda \\
\frac{1}{\lambda_{i}}=\frac{1}{\lambda+c_{7} \beta}-\frac{c_{8}}{\beta^{3}+1}
\end{array}\right.
$$

where $\lambda_{i}$ is intermediate variables; $c_{1}-c_{8}$ are polynomial coefficients. The values of $c_{1}-c_{8}$ of FD-77-1500III DFIG after fitting and setting are $c_{1}=0.5176, c_{2}=116, c_{3}=0.4, c_{4}=5, c_{5}=21, c_{6}=0.0068$, $c_{7}=0.08, c_{8}=0.035$, respectively. $C_{P}$ curves are shown in Figure 1 . When $\beta$ is constant, there is an optimal tip speed ratio which maximizes the $C_{P}$ value.

The tip speed ratio $\lambda$ is defined as the ratio of the tip circumferential velocity of the WT blade to the wind speed, which is given by [27]:

$$
\lambda=\frac{\omega_{r} R}{v}
$$

where $\omega_{\mathrm{r}}$ is the angular frequency of WT; $R$ is the radius of WT.

In the traditional control mode, the value of $\omega_{\mathrm{r}}$ is changed so that the ratio of $\omega_{\mathrm{r}}$ to $v$ is maintained at optimal tip speed ratio to achieve maximum captured power at different wind speeds.

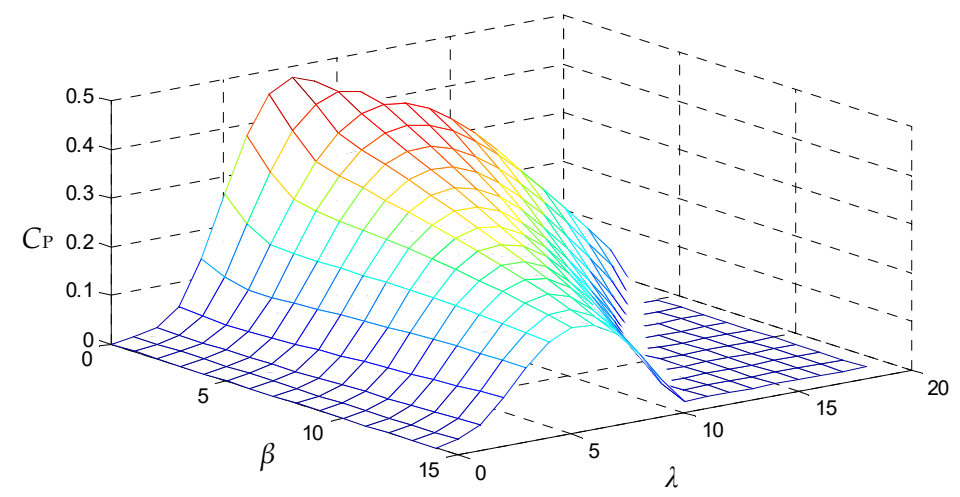

Figure 1. $C_{P}-\lambda-\beta$ characteristic curves.

\section{Analysis of Frequency Regulation Method of DFIG with Different Wind Speeds}

\subsection{Conditions of DFIG Participating in Bidirectional Frequency Regulaiton}

The DFIG has no reserve active power, and cannot regulate upwards the frequency of the system under the traditional control mode. The WT participating in the bidirectional frequency regulation is bound to reduce the initial operation point, then reserve part of power to provide bidirectional frequency support for the system. As shown in Equations (1)-(3), changing $C_{P}$ can adjust the mechanical power of the WT. $C_{\mathrm{P}}$ is a function of $\omega_{\mathrm{r}}$ and $\beta$, therefore, adjusting $\omega_{\mathrm{r}}$ and $\beta$ can change the WT output power, and then the WT achieves bidirectional regulation capability.

When the wind speed is $v$, the power reservation coefficient $d$ can be expressed as:

$$
d=\frac{P_{\mathrm{Wopt}}(v)-P_{\mathrm{Wre}}(v)}{P_{\mathrm{Wopt}}(v)}
$$

where: $P_{\text {Wopt }}(v)$ is the maximum captured power at the wind speed $v, P_{\text {Wre }}(v)$ is the initial operation power at the wind speed $v$.

With the WT is operating in maximum power tracking area as an example, the schematic diagram of the WT deloading operation at wind speed $v$ is shown in Figure 2: The maximum power point 
is at point $\mathrm{A}$, the corresponding rotor speed is $\omega_{\mathrm{opt}}$ and the output power is $P_{\text {Wopt }}$. When the rotor overspeeds to point $B$, the rotor speed reaches the rated rotor speed $\omega_{\mathrm{N}}$, and the output power is $P_{\mathrm{Wr} \text { n }}$, then the reservation power is $\Delta P_{\text {Wrer }}$. In order to further increase the reservation power to get the $d$ level, adjust the pitch angle to be greater than $0^{\circ}$, then the WT operates to point $C$, and the additional reservation power is $\Delta P_{\text {Wrep }}$ through the pitch regulation. Therefore, under different wind speeds, $P_{\text {Wre }}(v)$ can be expressed as:

$$
P_{\text {Wre }}(v)=P_{\text {Wopt }}(v)-\Delta P_{\text {Wrer }}(v)-\Delta P_{\text {Wrep }}(v)
$$

If the WT operates at low wind speeds, the rotor speed regulation is sufficient to reach the power reservation coefficient level, then $\Delta P_{\text {Wrep }}(v)=0$. If the WT operates in a constant speed area or constant power area, the rotor speed has reached the rated rotor speed, and the rotor over-speed operation cannot reserve power, in this case $\Delta P_{\text {Wrer }}(v)=0$.

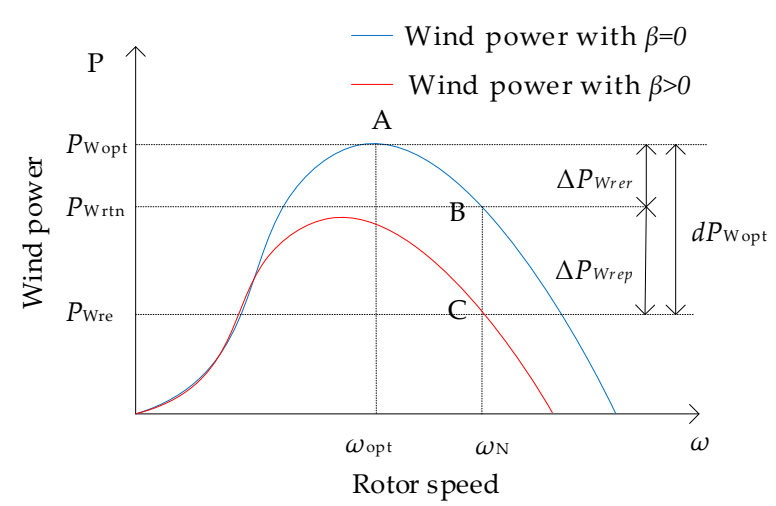

Figure 2. Schematic diagram of the WT de-loading operation at wind speed $v$.

\subsection{Bidirectional Regulation Power Constraints under Rotor Speed Regulation}

As shown in Equations (2) and (3), the WT output power is a function of $\omega$ and $\beta$ at a certain wind speed, it can be expressed as $f(\omega, \beta)$. When the WT participates in the frequency regulation through rotor speed regulation, the regulation power is $\Delta P_{\mathrm{Wfr}}(v)$, and the corresponding rotor speed $\omega_{\mathrm{r}}$ is:

$$
\left\{\begin{array}{l}
C_{\mathrm{Pr}}=\frac{\left(P_{\mathrm{Wre}}(v)+\Delta P_{\mathrm{Wfr}}(v)\right) C_{\mathrm{Pmax}}}{P_{\text {Wopt }}(v)} \\
\omega_{\mathrm{r}}=f^{-1}\left(C_{\mathrm{pr}}, \beta=0\right)
\end{array}\right.
$$

where $C_{\mathrm{pmax}}$ is the wind energy utilization coefficient when the WT operates in the MPPT mode. $C_{\mathrm{pr}}$ is the wind energy utilization coefficient after the WT regulates the frequency through rotor speed regulation. Due to the self-operating characteristics of the $\mathrm{WT}$, the regulation power $\Delta P_{\mathrm{Wfr}}(v)$ under rotor speed regulation is constrained. The specific constraints are analyzed as follows.

As shown in Figure 2, the available regulation power is constrained by the rated speed through rotor speed regulation. With the different wind speeds, the maximum regulation power $\Delta P_{\text {os }}(v)$ under the rotor speed regulation is expressed as:

$$
\Delta P_{\mathrm{os}}(v)=P_{\mathrm{Wopt}}(v)-P_{\mathrm{Wrtn}}(v)
$$

The available upward regulation power $\Delta P_{\text {Wup }}(v)$ and the available downward regulation power $\Delta P_{\mathrm{Wdn}}(v)$ of the WT are constrained by $\Delta P_{\mathrm{os}}(v)$, the constraints are as follows:

$$
\Delta P_{\mathrm{os}}(v)=\Delta P_{\mathrm{Wup}}(v)+\Delta P_{\mathrm{Wdn}}(v)
$$


When the power reservation coefficient is $d, \Delta P_{\mathrm{Wup}}(v)$ and $\Delta P_{\mathrm{Wdn}}(v)$ are expressed as:

$$
\left\{\begin{array}{c}
\Delta P_{\mathrm{Wup}}(v)=\frac{1}{2} \rho S v^{3}(1-d) C_{\mathrm{pmax}} \\
\Delta P_{\mathrm{Wdn}}(v)=\Delta P_{\mathrm{os}}(v)-\Delta P_{\mathrm{Wup}}(v)
\end{array}\right.
$$

As shown in Equations (8) and (9): The WT reserves power and have the available upward regulation power (supporting the negative frequency difference events of the system), but at the same time, it reduces the available downward regulation power and weakens the ability of regulating the positive frequency difference events of the system.

The optimal rotor speed of the WT is close to the rated speed at high wind speeds, and the reservation power cannot get the power reservation coefficient $d$ level through the rotor speed regulation. At this time, $\Delta P_{\mathrm{Wup}}(v)$ and $\Delta P_{\mathrm{Wdn}}(v)$ are expressed as:

$$
\left\{\begin{aligned}
\Delta P_{\mathrm{Wup}}(v) & =\Delta P_{\mathrm{os}}(v) \\
\Delta P_{\mathrm{Wdn}}(v) & =0
\end{aligned}\right.
$$

Equation (10) shows that the reservation power is the maximum regulation power, and the available downward regulation power is zero at high wind speeds. In this case, as the power reservation coefficient increases, the wind speed interval without available downward regulation power will increase. If a positive frequency difference event occurs at this time, the WT cannot participate in the frequency regulation and cause the loss of reservation power.

The above analysis indicates that the available upward and downward regulation power are constrained by the maximum regulation power and the power reservation coefficient. Therefore, the bidirectional regulation power constraints should be taken into account when designing the power reservation coefficient.

The available regulation power of the FD-77-1500III DFIG with different reservation coefficients is shown in Figure 3. When the wind speed is $6 \mathrm{~m} / \mathrm{s}$, the maximum regulation power is the largest (0.044 p.u.). When the wind speed is greater than $8 \mathrm{~m} / \mathrm{s}$, the maximum regulation power is significantly reduced, and the frequency regulation capability is reduced. The available upward and downward regulation power are related to the wind speed and the reservation coefficient. At a certain wind speed, the larger the reservation coefficient is, the lower the available downward regulation power is.

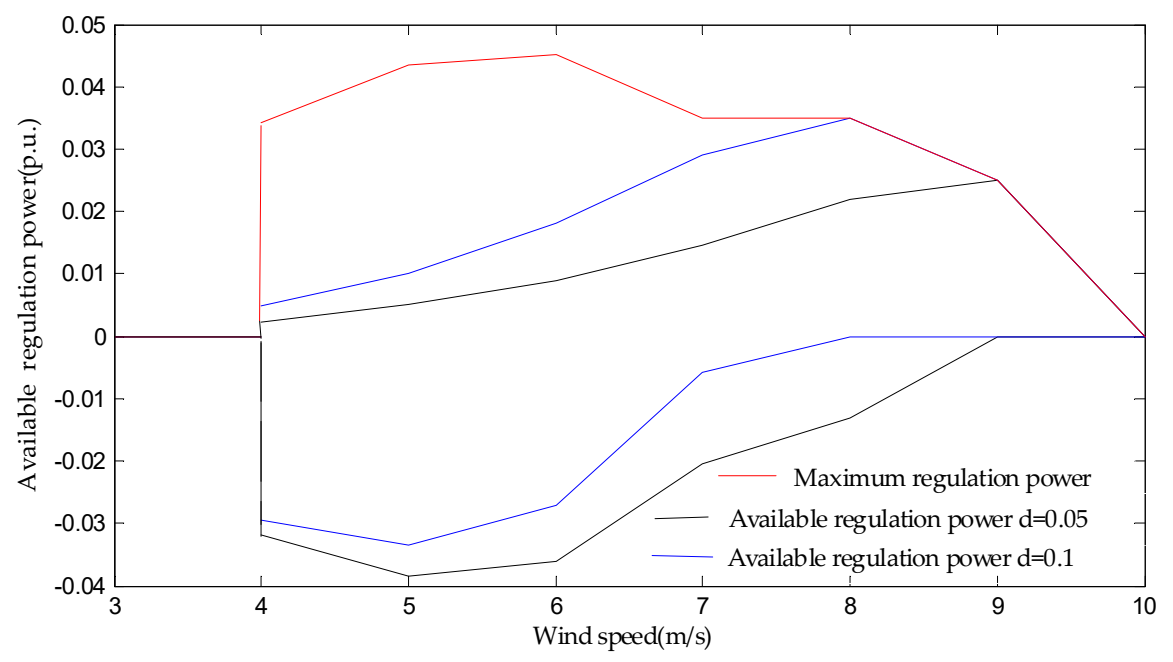

Figure 3. Available regulation power under the rotor speed regulation with different reservation coefficients. 


\subsection{Regulation Power Constraints under Pitch Regulation}

The above analysis shows that the available bidirectional regulation power of the WT obtained by the rotor speed regulation is small at medium wind speeds, and in order to get larger regulation power, the pitch angle should be adjusted to meet the demand of larger regulation power. At high wind speeds, it is impossible to get bidirectional regulation power through rotor speed regulation, in this case, the pitch regulation should be adopted.

The rotor speed has reached $\omega_{N}$ when the pitch is regulated. When the regulation power is $\Delta P_{\mathrm{wfp}}(v)$ through the pitch regulation, the calculation of pitch angle $\beta$ is as follows:

$$
\left\{\begin{array}{l}
C_{\mathrm{pp}}=\frac{\left(P_{\mathrm{Wre}}(v)+\Delta P_{\mathrm{Wfr}}(v)+\Delta P_{\mathrm{wfp}}(v)\right) C_{\mathrm{Pmax}}}{P_{\mathrm{Wopt}}(v)} \\
\beta=f^{-1}\left(C_{\mathrm{pp}}, \omega=\omega_{\mathrm{N}}\right)
\end{array}\right.
$$

where $C_{\mathrm{pp}}$ is the wind energy utilization coefficient after rotor speed and pitch angle regulation.

The pitch angle adjustment of DFIG is accomplished by a hydraulic pitch actuator. The pitch action has a certain degree of hysteresis, which leads to a certain delay in primary frequency regulation with pitch regulation. At present, the delay of hydraulic pitch mechanism has not exceeded $1 \mathrm{~s}$, the pitch speed can reach $5^{\circ} / \mathrm{s}$ under the maximum load [28]. The duration of primary frequency regulation of the power system is 10-30 s [29]. In order to meet the primary frequency regulation requirements of the power system on the time scale, it is necessary to avoid the excessive regulation of pitch angle, which will lead to regulation time too long.

When the rotor speed at the rated speed, the curve of $C_{\mathrm{P}}-\beta$ with different wind speeds of the FD-77-1500III DFIG is shown in Figure 4. The tip speed ratio decreases with the increase of wind speed. Therefore, at a certain pitch angle, the greater the wind speed is, the smaller the $C_{P}$ is.

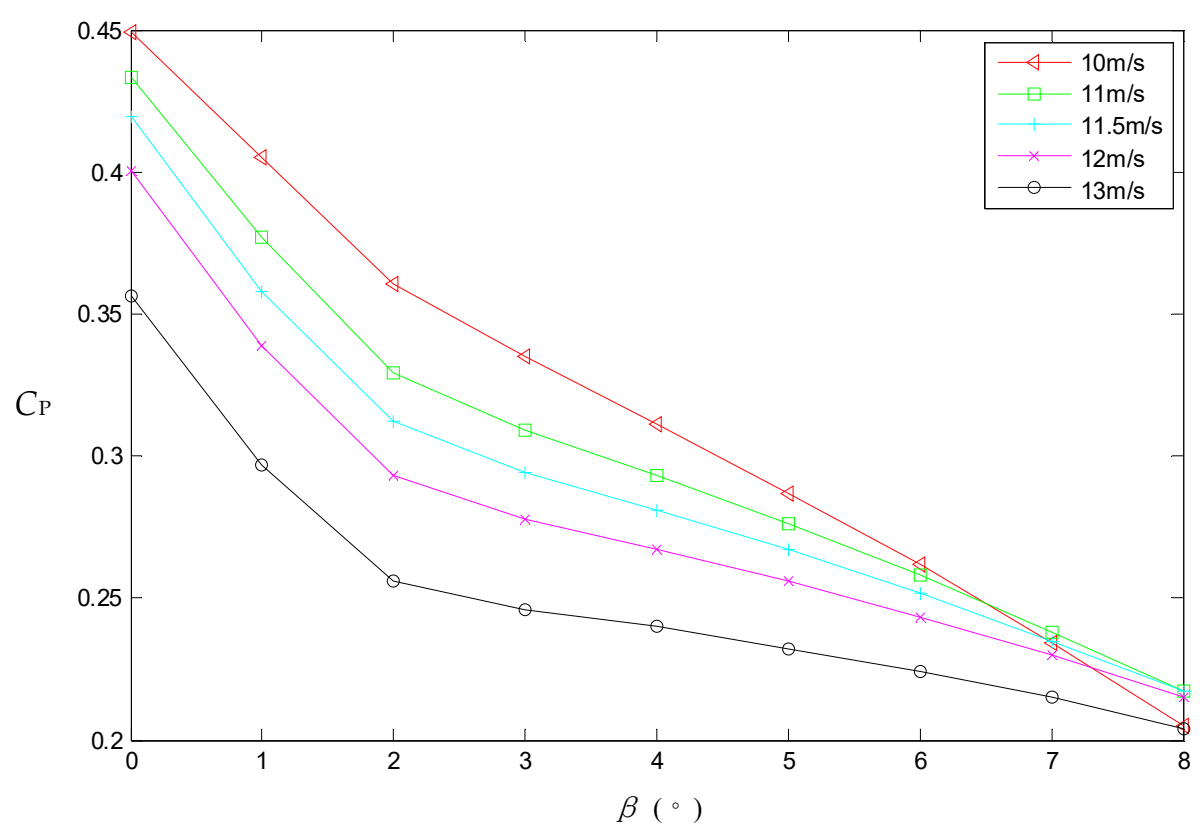

Figure 4. $C_{\mathrm{P}}-\beta$ characteristic curves of the FD-77-1500III DFIG with different wind speeds.

As shown in Figure 4, under the different wind speeds, the $C_{\mathrm{P}}-\beta$ curve is an approximate linear relationship. Through linear fitting calculating, when $\beta$ changes $4^{\circ}$, the $C_{P}$ is about 0.7 times of the traditional control mode's value, that is, the wind power is reduced by about $30 \%$. The data of different wind speeds when the pitch increases by $4^{\circ}$ as shown in Table 1 . In the table, $C_{P}$ of pitch increasing $4^{\circ}$ represents the $C_{P}$ of pitch increasing by $4^{\circ}$ on the basis of traditional control. Regulation power (\%) represents the percentage of the regulation power to the maximum captured power. 
Table 1. The data of different wind speeds when the pitch increases by $4^{\circ}$.

\begin{tabular}{cccccc}
\hline Parameter & $\mathbf{1 0 ~ \mathbf { ~ } / \mathbf { s }}$ & $\mathbf{1 1 ~ \mathbf { ~ } / \mathbf { s }}$ & $\mathbf{1 1 . 5} \mathbf{~ m} / \mathbf{s}$ & $\mathbf{1 2 ~ \mathbf { ~ } / \mathbf { s }}$ & $\mathbf{1 3 ~ \mathbf { ~ } / \mathbf { s }}$ \\
\hline C $_{\mathrm{P}}$ of traditional control & 0.449 & 0.392 & 0.346 & 0.305 & 0.24 \\
C $_{\mathrm{P}}$ of pitch increasing 4 & 0.302 & 0.278 & 0.249 & 0.220 & 0.173 \\
Regulation power $(\%)$ & 32.7 & 29.1 & 28.0 & 27.9 & 27.9 \\
\hline
\end{tabular}

The time of pitch angle action $4^{\circ}$ is generally about $1 \mathrm{~s}$, which can meet the requirements of primary frequency regulation of the power system on time scale. Therefore, this paper conservatively designs that the pitch regulation angle constraint is $4^{\circ}$, and the regulation power constraint is about $30 \%$.

\section{Control Strategy of DFIG Participating in Frequency Regulation with Different Wind Speeds}

\subsection{Effects of Regulation Power Constraints on DFIG Participating in Frequency Regulation}

The traditional synchronous generator participates in the primary frequency regulation of the system, adjusts the output power by the governor changing the opening value of the intake. The synchronous generators in the system divide the active regulation power according to the value of the adjustment coefficient. The smaller the adjustment coefficient is, the larger regulation power will be distributed. The adjustment coefficient of synchronous generator $\sigma_{\mathrm{G}}$ is defined as [30]:

$$
\sigma_{\mathrm{G}}=\frac{\Delta f^{*}}{\Delta P_{\mathrm{G}}^{*}}=\frac{\Delta f / f_{\mathrm{N}}}{\Delta P_{\mathrm{G}} / P_{\mathrm{GN}}}
$$

where $P_{\mathrm{GN}}$ is the rated power of synchronous generator, $\Delta P_{\mathrm{G}}$ is the regulation power when the frequency difference is $\Delta f, f_{\mathrm{N}}$ is the rated frequency of system. $\Delta f^{*}$ is the per-unit value of $\Delta f, \Delta P_{\mathrm{G}}{ }^{*}$ is the per-unit value of $\Delta P_{\mathrm{G}}$. In general, the turbo-generator $\sigma_{\mathrm{G}}$ is set at $3 \%-5 \%$, and the hydro-generator $\sigma_{\mathrm{G}}$ is set at $2 \%-4 \%$.

We design the adjustment coefficient of the DFIG to participate in primary frequency regulation of the system with the similar power-frequency characteristics as the traditional synchronous generator. The adjustment coefficient of the WT is defined as:

$$
\sigma_{\mathrm{W}}=\frac{\Delta f^{*}}{\Delta P_{\mathrm{W}}^{*}}=\frac{\Delta f / f_{\mathrm{N}}}{\Delta P_{\mathrm{W}} / P_{\mathrm{WN}}}
$$

where $P_{\mathrm{WN}}$ is the rated power of $\mathrm{WT}, \Delta P_{\mathrm{W}}$ is the regulation power of WT when the frequency difference is $\Delta f, \Delta P_{\mathrm{W}}{ }^{*}$ is the per-unit value of $\Delta P_{\mathrm{W}}$.

The WT is affected by the bidirectional regulation power constraints. In some wind speed-frequency difference events, the WT cannot provide regulation power according to the adjustment coefficient, which reflects the increase of actual adjustment coefficient. At a certain wind speed, when the available upward and downward regulation power are $\Delta P_{\text {Wup }}(v)$ and $\Delta P_{\text {Wdn }}(v)$ respectively, the frequency difference range is $\left[\Delta f_{\mathrm{dn}, \min }(v), \Delta f_{\mathrm{up}, \max }(v)\right]$, in which the WT can provide regulation power according to adjustment coefficient. $\Delta f_{\mathrm{dn}, \min }(v)$ and $\Delta f_{\mathrm{up}, \max }(v)$ can be expressed as:

$$
\begin{gathered}
\Delta f_{\mathrm{dn}, \min }(v)=\frac{-\sigma_{\mathrm{W}} \Delta P_{\mathrm{Wup}}(v) f_{\mathrm{N}}}{P_{\mathrm{WN}}} \\
\Delta f_{\mathrm{up}, \max }(v)=\frac{\sigma_{\mathrm{W}} \Delta P_{\mathrm{Wdn}}^{*}(v) f_{\mathrm{N}}}{P_{\mathrm{WN}}}
\end{gathered}
$$

where $\Delta f_{\mathrm{dn}, \min }(v)$ is the lower limit of the range, and $\Delta f_{\mathrm{up}, \max }(v)$ is the upper limit of the range.

If the frequency difference is between $\Delta f_{\mathrm{dn} \text {, } \min }(v)$ and $\Delta f_{\text {up,max }}(v)$, the actual adjustment coefficient is the setting coefficient. Beyond this range, the actual coefficient is greater than the setting coefficient. This frequency difference range is different with different wind speeds, because the bidirectional frequency regulation power is different under different wind speeds. 


\subsection{Control Strategy of DFIG Participating in Frequency Regulation}

The synchronous generators in the system divide the active regulation power according to the adjustment coefficient value. However, unlike the primary frequency regulation of the synchronous generator, the WT is affected by the bidirectional regulation power constraints, when the frequency difference exceeds the range of $\Delta f_{\mathrm{dn}, \min }(v)$ and $\Delta f_{\text {up,max }}(v)$, the regulation power of the WT is less than the divided active regulation power, which leads to the degradation of the WT frequency regulation effects. Therefore, when the WT participates in primary frequency regulation, new control links should be added, and according to different wind speeds, corresponding control strategy needs to be adopted.

As shown in Figure 3, when the wind speed is in the range of $4 \mathrm{~m} / \mathrm{s}$ to $6 \mathrm{~m} / \mathrm{s}$ (low wind speed range), the available bidirectional regulation power has a large regulation range, so the rotor speed control strategy is adopted in this wind speed range. When the wind speed is in the range of $6 \mathrm{~m} / \mathrm{s}$ to $10 \mathrm{~m} / \mathrm{s}$ (medium wind speed range), the available bidirectional regulation power is small, so the rotor speed and pitch coordinated control strategy is adopted in this wind speed range. When the wind speed is greater than $10 \mathrm{~m} / \mathrm{s}$ (high wind speed range), the bidirectional regulation power cannot be obtained by the rotor speed regulation, so the pitch control strategy is adopted in this wind speed range.

The control structure diagram of the DFIG participating in frequency regulation with different wind speeds is shown in Figure 5. $T_{\mathrm{W}}$ is the inertia time constant. $K_{\mathrm{W}}$ is the frequency characteristic coefficient, which is the reciprocal of $\sigma_{\mathrm{W}} . \omega_{\max }, \omega_{\min }$ are the rotor speed limit values. $T_{\mathrm{S}}$ is the delay of pitch servo drive system. $\frac{d \beta}{d t} \max ^{\prime} \frac{d \beta}{d t} \min$ are the pitch rate limits. $\beta_{\max }, \beta_{\min }$ are the pitch amplitude limits.

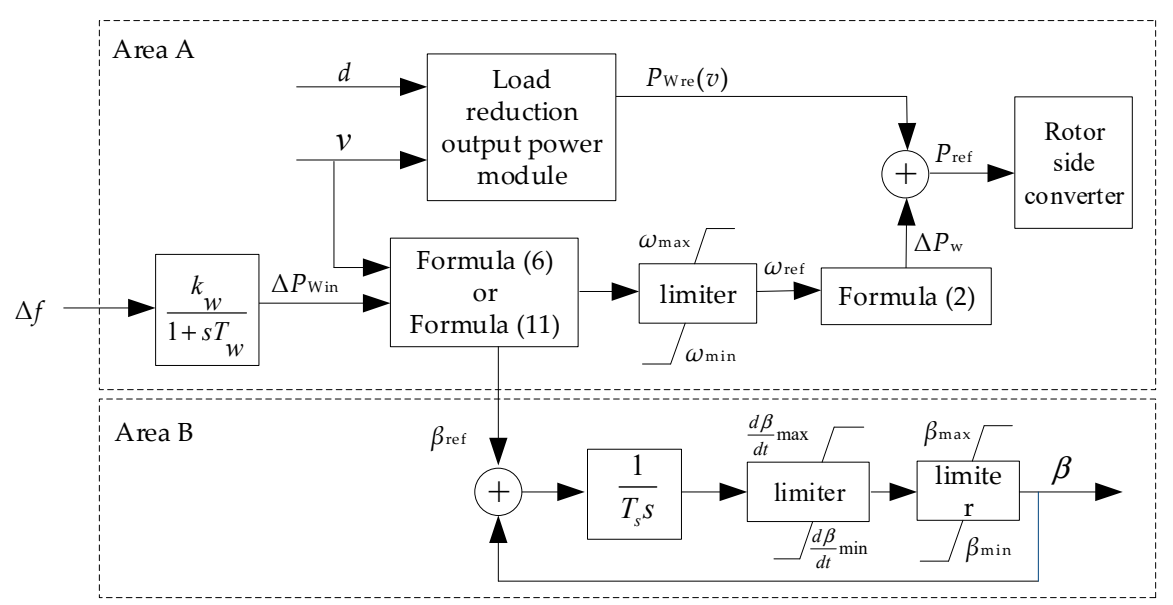

Figure 5. Control structure diagram of DFIG participating in frequency regulation with different wind speeds.

As shown in Figure 5, there are two areas of the control structure diagram. Area A is the WT output power module. When the system frequency difference is $\Delta f$, the regulation power of the WT distributed by the setting adjustment coefficient is $\Delta P_{\text {Win }}$. When the wind speed is $v$, the regulation power provided by the WT is $\Delta P_{\mathrm{W}}$ under the regulation power constraints. $\Delta P_{\mathrm{W}}$ is added to the initial operation power $P_{\mathrm{Wre}}(v)$ as the active power reference value of the rotor-side converter. Area $\mathrm{B}$ is the pitch angle regulation module. The reference value $\beta_{\text {ref }}$ of the pitch angle is calculated according to the Equation (11). The pitch angle $\beta$ is obtained by the servo drive delay system, the pitch rate limiting link, and the pitch amplitude limiting link.

\section{Simulation Verification and Analysis}

In order to verify the frequency regulation capability and effects of WTs participating in the long-term continuous frequency regulation process, the equivalent model including a wind farm and a thermal power unit is constructed. The wind farm consists of 66 DFIGs, and single capacity is $1.5 \mathrm{MW}$. 
The capacity of thermal power unit is $600 \mathrm{MW}$. The total load is $560 \mathrm{MW}$. The simulation model of the system is shown in Figure 6. Thermal power unit inertia time constant is $8.84 \mathrm{~s}, \sigma_{\mathrm{G}}=4 \%$. Loads L1 and L2 are $260 \mathrm{MW}$ and $300 \mathrm{MW}$, respectively. The unit regulation power coefficient of load is 1.5 . The WT inertia time constant is $2 \mathrm{~s}$. Design $\sigma_{\mathrm{W}}=4 \%$, which makes the DFIG have the equivalent power-frequency characteristics as the synchronous generator. The delay of pitch servo drive system $T \mathrm{~s}=0.25 \mathrm{~s}[31]$.

In addition, the difference characteristics of the WTs in wind farm and the difference of control time is neglected in this paper, and the characteristics of one WT are equivalent to a wind farm.

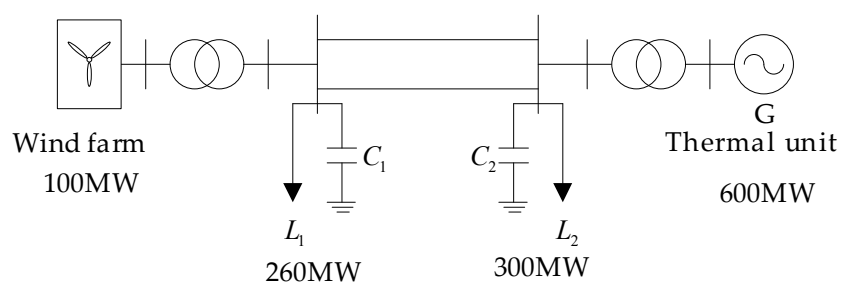

Figure 6. Simulation model of the system.

\subsection{Frequency Dynamic Process Simulation under Single Frequency Disturbance}

\subsubsection{Simulation Verification of Rotor Speed Frequency Regulation Control Strategy}

We set the wind speed to $8 \mathrm{~m} / \mathrm{s}$, power reservation coefficient $d=0.05$. The simulation results of the load step change are shown in Figure 7, where when the WT does not participate in the frequency regulation, the initial rotor speed (optimal rotor speed) is $1410 \mathrm{rpm}$, and the output power (maximum captured power) is 0.4363 p.u. $(654.45 \mathrm{~kW})$. When the WT participates in frequency regulation, the initial rotor speed is $1610 \mathrm{rpm}$, and the output power is $0.4146 \mathrm{p} . \mathrm{u}$. (621.9 $\mathrm{kW})$, and the reservation power is $5 \%$.

The load step increase by $20 \mathrm{MW}$ at $5 \mathrm{~s}$, as shown in the Figure 7a-c: The system frequency decreases. When the WT participates in the frequency regulation, the WT operates at the maximum power point after the system is stable, releases all the reservation power to participate in frequency regulation, the frequency difference is stable at $-0.0563 \mathrm{~Hz}$, which is $10.8 \%$ less than that of the WT without frequency regulation.

The load step decrease by $20 \mathrm{MW}$ at $5 \mathrm{~s}$, as shown in the Figure $7 \mathrm{~d}-\mathrm{f}$ : The system frequency increases. When the WT participates in frequency regulation, the rotor speed is accelerated to the rated rotor speed $1750 \mathrm{rpm}$, the output power is reduced to $0.4031 \mathrm{p} . \mathrm{u}$. (604.65 kW) after the system is stable, the frequency difference is stable at $0.0599 \mathrm{~Hz}$, which is $5.8 \%$ less than that of the WT without frequency regulation. 


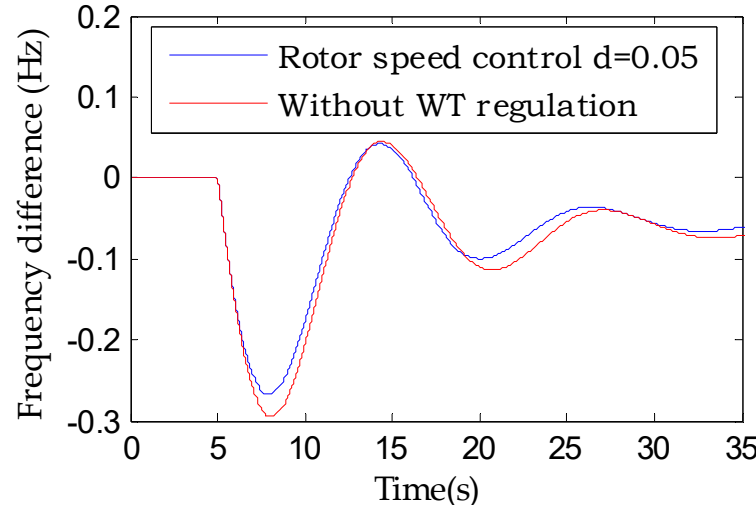

(a) Frequency difference (load increase)

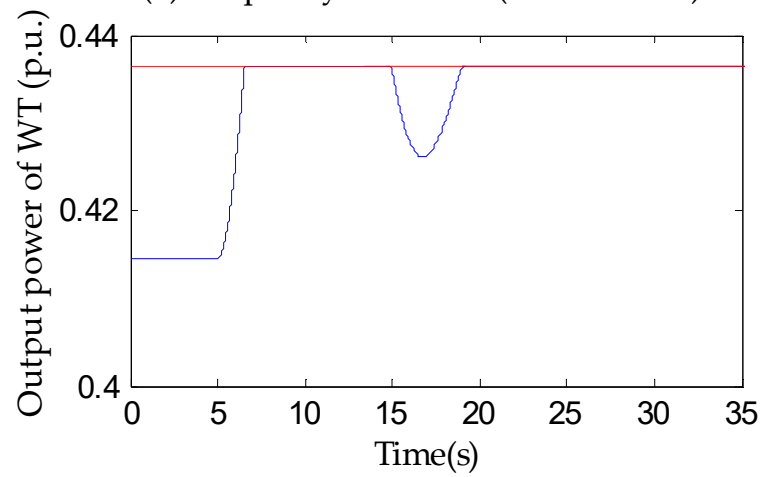

(b) Wind power (load increase)

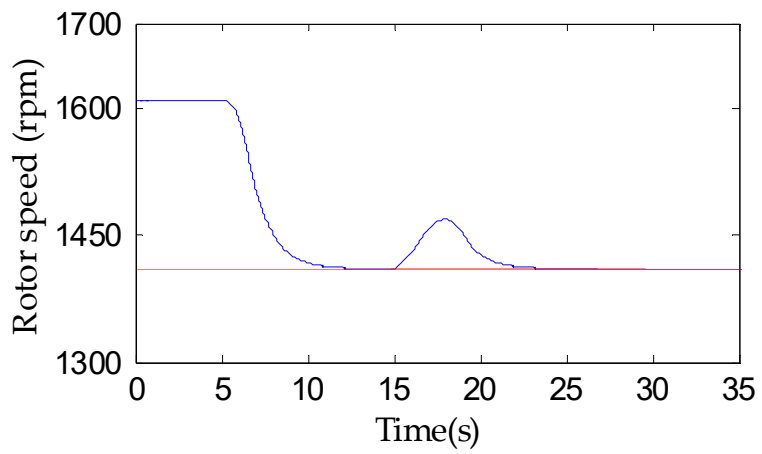

(c) Rotor speed (load increase)

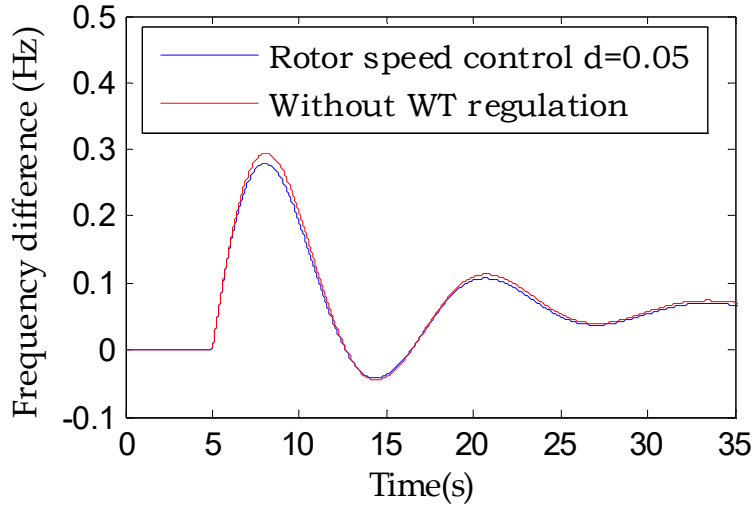

(d) Frequency difference (load decrease)

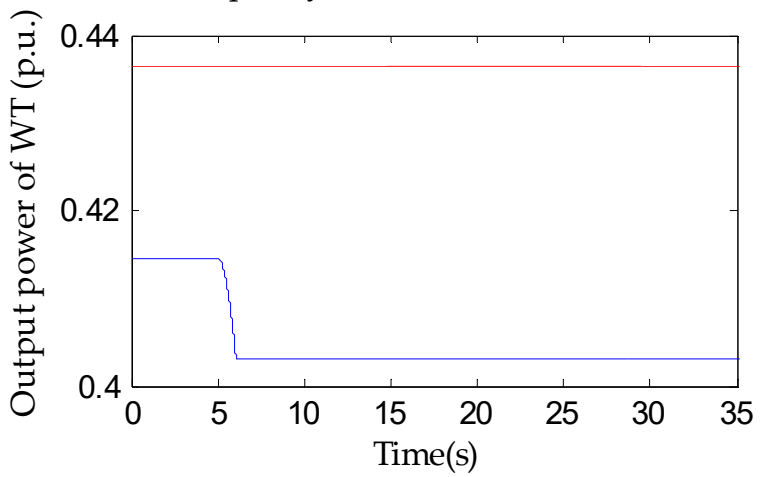

(e) Wind power (load decrease)

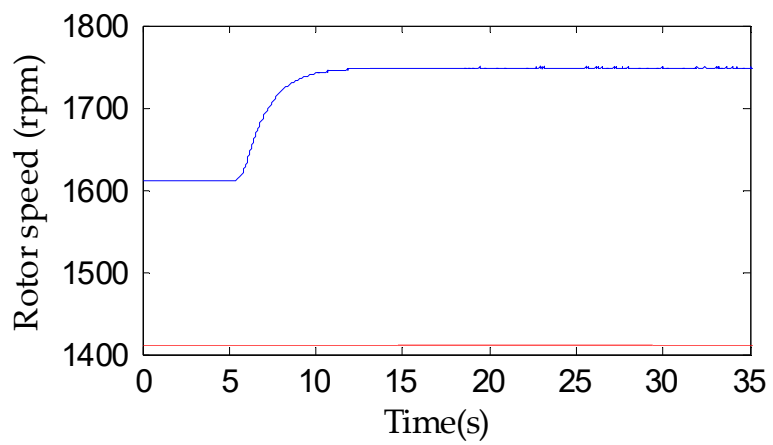

(f) Rotor speed (load decrease)

Figure 7. Dynamic responses during load step change under the rotor speed control Strategy. Figures (a)-(c) respectively show the frequency difference, wind power, and rotor speed comparison between a WT participating in and not participating in frequency regulation during a load step increase; figures (d)-(f) respectively show the frequency difference, wind power, and rotor speed comparison between a WT participating in and not participating in frequency regulation during a load step decrease.

\subsubsection{Simulation Verification of Pitch Frequency Regulation Control Strategy}

Set wind speed to $12 \mathrm{~m} / \mathrm{s}$ and the power reservation coefficient to $d=0.05$. The simulation results of the load step change are shown in Figure 8.

As shown in the Figure 8, when the WT does not participate in frequency regulation, the pitch angle $\beta=2.4^{\circ}$, and the output power is $1 \mathrm{p} . \mathrm{u}$. When the WT participates in frequency regulation, the initial pitch angle $\beta=2.9^{\circ}$, the output power is 0.95 p.u., and the reservation power is $5 \%$.

The load step increase by $20 \mathrm{MW}$ at $5 \mathrm{~s}$, as shown in the Figure $8 \mathrm{a}-\mathrm{c}$ : The system frequency decreases. When the WT participates in frequency regulation, the output power of the WT is increased to 0.9775 p.u. and the pitch angle is $2.623^{\circ}$ after the system is stable, the frequency difference is stable at $-0.0546 \mathrm{~Hz}$, which is $16.51 \%$ less than that of the WT without frequency regulation. 
The load step decrease $20 \mathrm{MW}$ at $5 \mathrm{~s}$, as shown in the Figure $8 \mathrm{~d}-\mathrm{f}$ : The system frequency increases. When the WT participates in the frequency regulation, the output power of WT is reduced to 0.9225 p.u. and the pitch angle is $3.1578^{\circ}$ after the system is stable, the frequency difference is stable at $0.0546 \mathrm{~Hz}$, which is $15.87 \%$ less than that of the WT without frequency regulation.

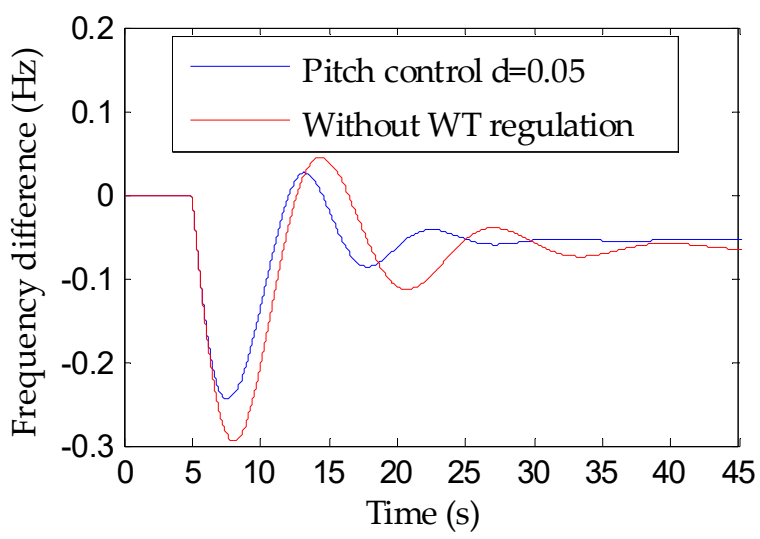

(a) Frequency difference (load increase)

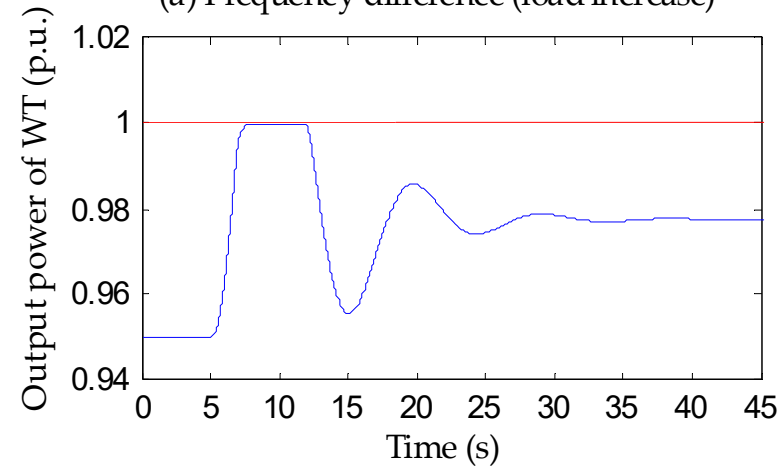

(b) Wind power (load increase)

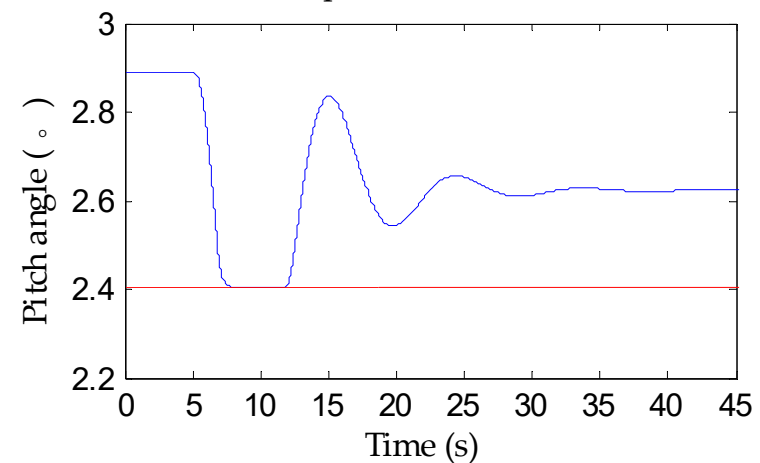

(c) Pitch angle (load increase)

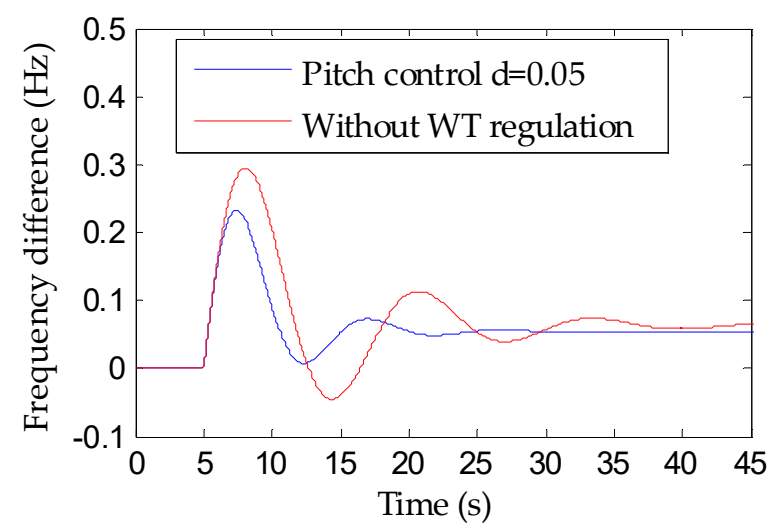

(d) Frequency difference (load decrease)

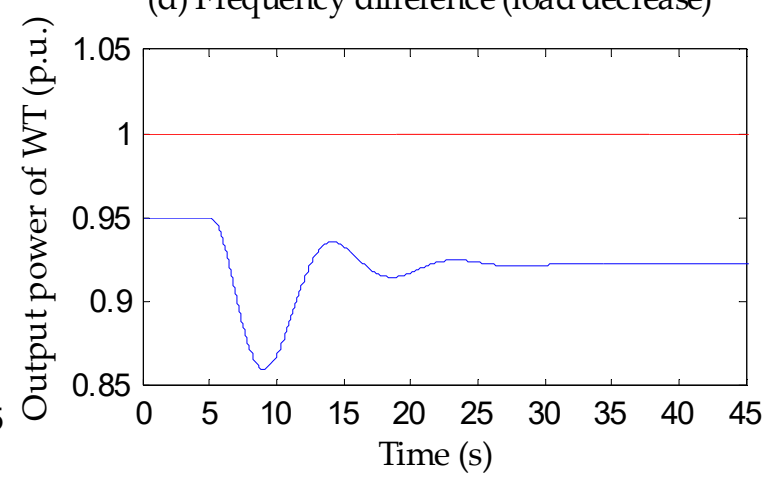

(e) Wind power (load decrease)

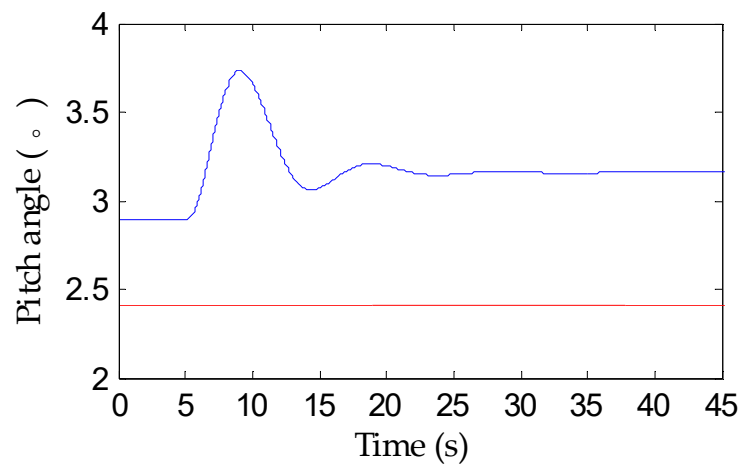

(f) Pitch angle (load decrease)

Figure 8. Dynamic responses during load step change under the pitch control strategy. Figures (a)-(c) respectively show a frequency difference, wind power, pitch angle comparison between a WT participating in and not participating in frequency regulation during a load step increase; Figures (d)-(f) respectively show a frequency difference, wind power, pitch angle comparison between a WT participating in and not participating in frequency regulation during a load step decrease.

\subsection{Initial Operation Data of DFIG Participating in Frequency Regulation}

Long term continuous frequency regulation of WTs is a set of wind speed-frequency difference combination events, the combination affects the frequency regulation effects. Single frequency disturbances cannot characterize the capacity and effects of WTs participating in long term continuous frequency regulation. For this reason, this paper investigates the regulation power constraints of WTs 
and effects in the actual scenario of wind power fluctuation and frequency fluctuation on one day time scale.

One day wind speed of a wind farm is selected as the simulation data. Its intensity is equivalent to the annual utilization hours of typical wind farm (about 2000 hours [32]). The wind speed curve and statistical distribution are shown in Figure 9.

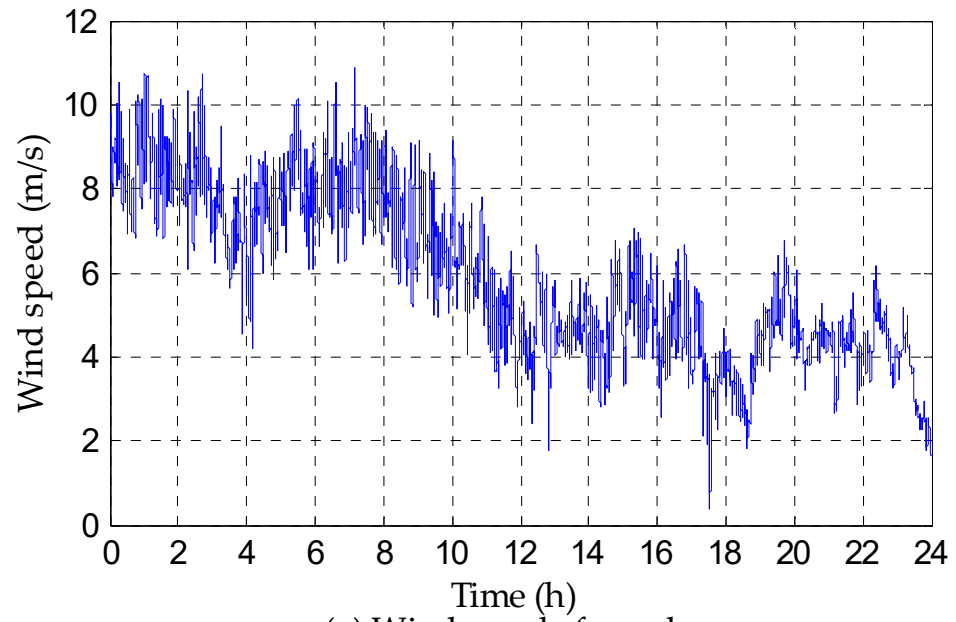

(a) Wind speed of one day

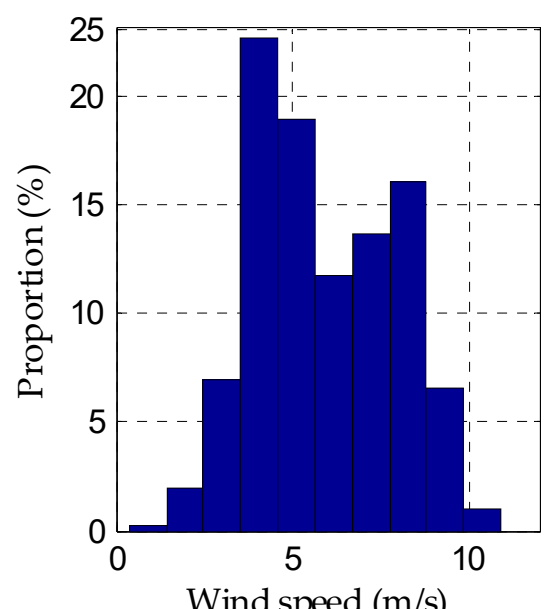

(b) Wind speed distribution

Figure 9. Wind speed and statistical distribution. (a) Wind speed; (b) statistical distribution.

As shown in Figure 9 the cumulative time of wind speed less than $4 \mathrm{~m} / \mathrm{s}$ is about $16.12 \%$, the wind speed between $4 \mathrm{~m} / \mathrm{s}$ and $6 \mathrm{~m} / \mathrm{s}$ is about $39 \%$, the wind speed between $6-10 \mathrm{~m} / \mathrm{s}$ is about $44.21 \%$, the wind speed is greater than or equal to $10 \mathrm{~m} / \mathrm{s}$, which is about $0.67 \%$. The equivalent load fluctuation curve is shown in Figure 10. The average value of equivalent load fluctuation absolute is $0.0011 \mathrm{MW}$, the maximum is $31.1717 \mathrm{MW}$, the minimum is $-34.3940 \mathrm{MW}$.

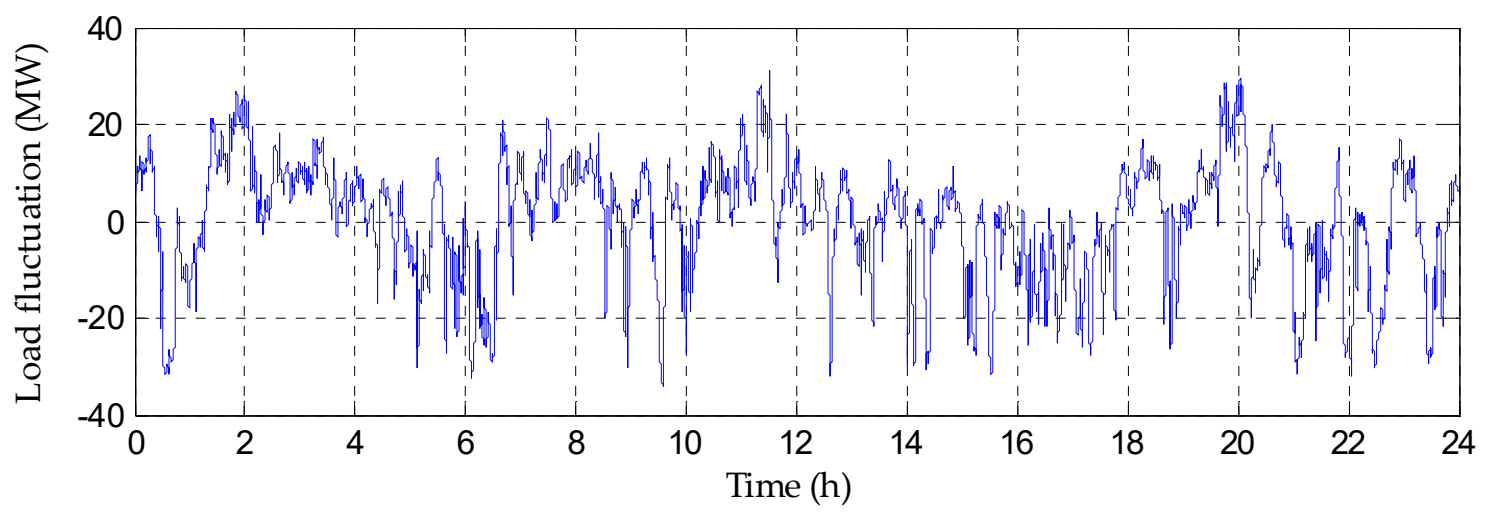

Figure 10. The equivalent load fluctuation curve.

\subsection{Simulation Analysis of Regulation Power Constraints and Effects under Rotor Speed Control Strategy}

The simulation results of different reservation coefficients under the rotor speed control strategy are shown in Table 2. 
Table 2. Simulation results of different reservation coefficients under the rotor speed control strategy.

\begin{tabular}{cccc}
\hline Parameter & No Regulation & $\boldsymbol{d}=\mathbf{0 . 0 5}$ & $\boldsymbol{d}=\mathbf{0 . 1}$ \\
\hline $\bar{d}$ & - & 0.0427 & 0.0786 \\
$\overline{\Delta f}$ (Hz) & 0.0313 & 0.0286 & 0.0287 \\
$\overline{\Delta P_{\mathrm{W}}}$ (p.u.) & - & 0.0084 & 0.0081 \\
$\overline{\sigma_{\mathrm{W}}}$ (\%) & - & 6.78 & 7.10 \\
\hline
\end{tabular}

In Table $2 \bar{d}$ is the average power reservation coefficient, $\overline{\Delta f}$ is the average value of frequency difference absolute, $\overline{\Delta P_{W}}$ is the average value of wind farm regulation power absolute, $\overline{\sigma_{W}}$ is the average adjustment coefficient of WT.

The data in Table 2 shows that compared with the WTs that do not participate in frequency regulation, when $d=0.05$ and $d=0.1, \overline{\Delta f}$ decreases by $8.63 \%$ and 8.31 , respectively. Compared with $d=0.05$, when $d=0.1, \overline{\Delta P_{W}}$ decreases by $3.57 \%$, and $\overline{\sigma_{W}}$ increases by $4.72 \%$.

The above data analysis shows that from the three aspects of frequency quality, regulation power and average adjustment coefficient, WTs participating in frequency regulation improves frequency quality of the system under the rotor speed control strategy, but the frequency regulation effects are not further improved with the increase of reservation coefficient. The main reason why the frequency regulation effects of $d=0.1$ is worse than that of $d=0.05$ is that: when $d=0.1, \bar{d}$ get $78.6 \%$ of the $\mathrm{d}$ level $(85.4 \%$ when $d=0.05)$, although $d$ increases, but the reservation power cannot be further increased at medium and high wind speeds, which limits the further improvement of the available upward regulation power. The increase of the reservation coefficient decreases the available downward regulation power. The data sequence of WTs without available downward regulation power when $d=0.1$ is selected for analysis, as shown in Figure 11 .
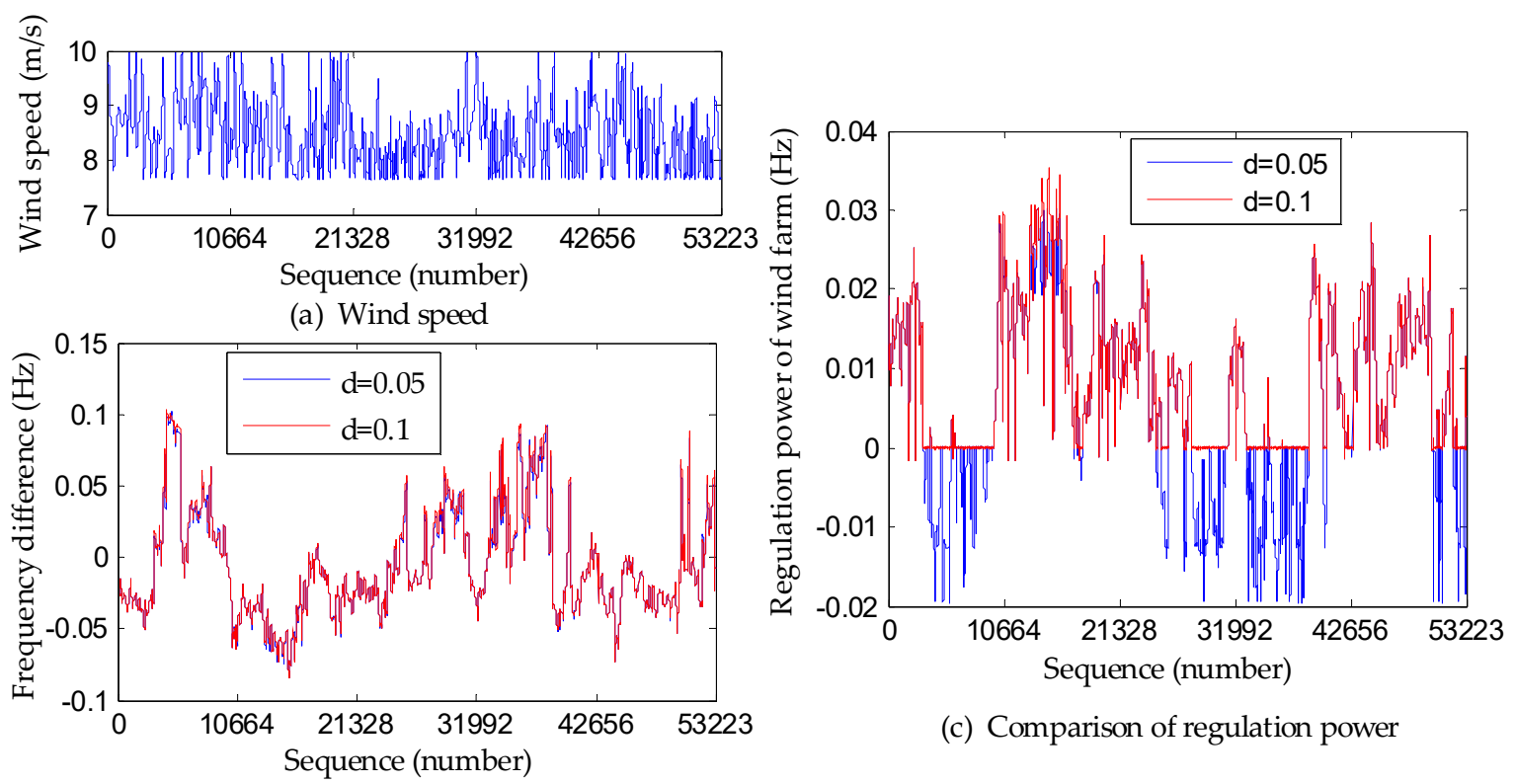

(b) Comparison of frequency difference

(c) Comparison of regulation power

Figure 11. Simulation results of the data sequence of no downward regulation power with $d=0.1$. (a) Wind speed; (b) Frequency difference comparison between $d=0.05$ and $d=0.1$; (c) Regulation power of wind farm comparison between $d=0.05$ and $d=0.1$.

As shown in Figure 11, when $d=0.1$, although the upward regulation power increases in the negative frequency difference events at some moments, the downward regulation power is zero in the positive frequency difference events at more moments. If a positive frequency difference event occurs at this time, it will affect the frequency regulation effects. When $d=0.1$ and $d=0.05$, the case of no 
downward regulation power and the positive frequency difference event occurring, it accounts for $8.78 \%$ and $2.14 \%$ of the total time respectively, $d=0.1$ is nearly 4.1 times higher than $d=0.05$, which lead to the overall frequency regulation effects of $d=0.1$ are worse than that of $d=0.05$.

The above analysis shows that due to the regulation power constraints, the frequency regulation effects are not improved with the increase of the power reservation coefficient under the rotor speed control in the designed example.

\subsection{Simulation Analysis under Rotor Speed and Pitch Coordinated Control Strategy}

Under the rotor speed control strategy, the available bidirectional regulation power at medium and high wind speeds is small or zero. The rotor speed and pitch coordinated control strategy is suitable for the WT participating in frequency regulation under different wind speeds. Under the coordinated control strategy, the simulation results with different reservation coefficients are shown in Table $3, \bar{\beta}$ is the average pitch angle action degree.

Table 3. Simulation results with different reservation coefficients under the coordinated control strategy.

\begin{tabular}{ccc}
\hline Parameter & $\boldsymbol{d}=\mathbf{0 . 0 5}$ & $\boldsymbol{d}=\mathbf{0 . 1}$ \\
\hline$\overline{\Delta f}(\mathrm{~Hz})$ & 0.0283 & 0.0281 \\
$\overline{\Delta P_{W}}$ (p.u.) & 0.0096 & 0.010 \\
$\overline{\sigma_{W}}(\%)$ & 5.88 & 5.46 \\
$\bar{\beta}\left({ }^{\circ}\right)$ & 0.0334 & 0.1501 \\
\hline
\end{tabular}

\subsubsection{Comparison of the Rotor Speed Control and Coordinated Control Strategy}

As shown in Tables 2 and 3, when $d=0.05$, compared with the rotor speed control, $\overline{\Delta f}$ decreases by $10.49 \%, \overline{\Delta P_{W}}$ increases by $14.07 \%$ and $\overline{\sigma_{W}}$ decreases by $13.27 \%$ under the coordinated control strategy. When $d=0.05$, the comparison of WTs participating in frequency regulation under the different control strategies is shown in Figure 12.

As shown in Figure 12, under the coordinated control strategy, the frequency difference of the system is significantly decreases and the regulation power of wind farm is significantly increases at medium and high wind speeds. According to statistics, when $d=0.05$, under the coordinated control strategy, the regulation power of wind farm does not get the adjustment coefficient, accounting for $23 \%$ of the total time, which is $12 \%$ less than that of rotor speed control strategy. Therefore, the average adjustment coefficient decreases under the coordinated control strategy. 


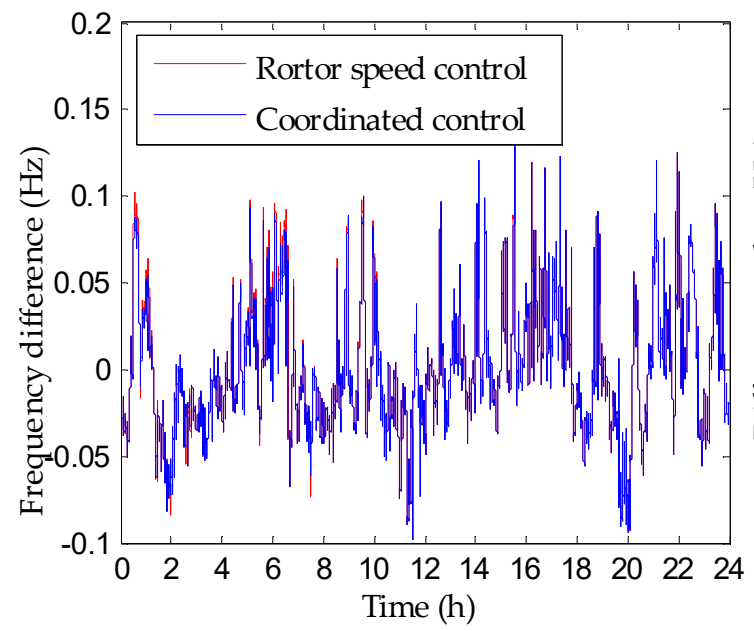

(a) Comparison of frequency difference

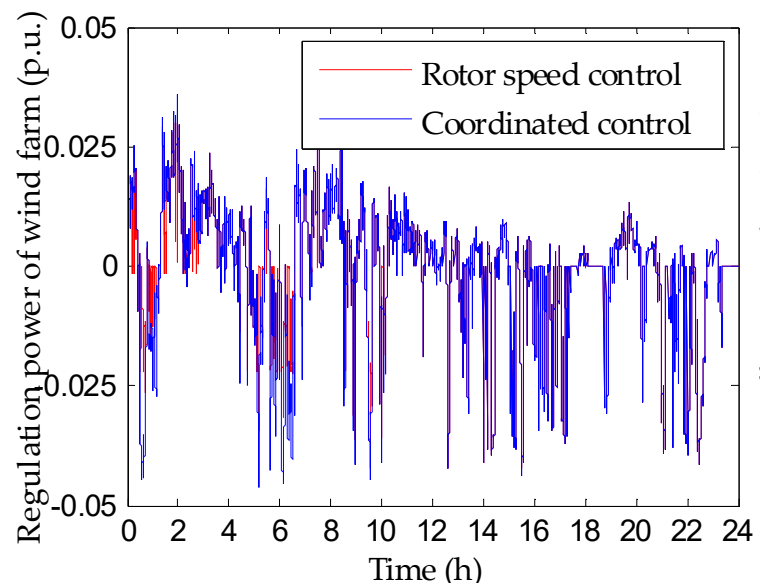

(c) Comparison of regulation power

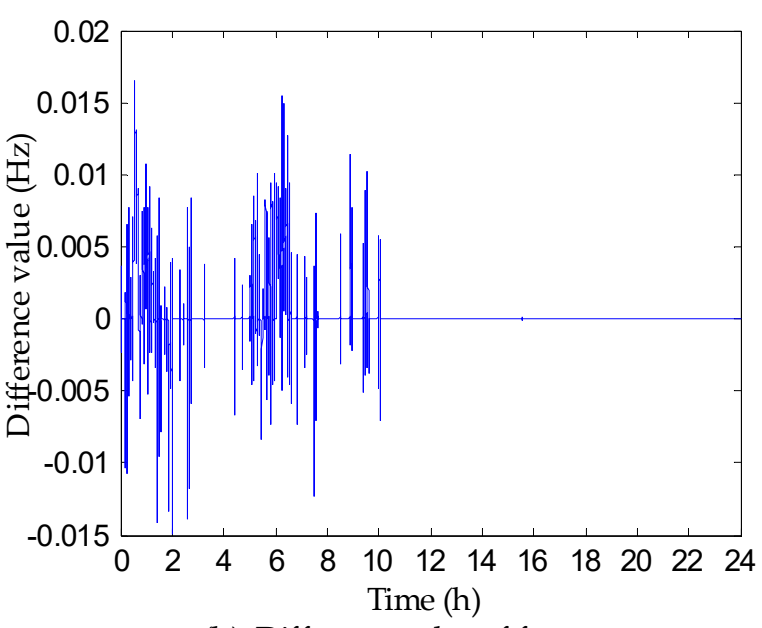

(b) Difference value of frequency

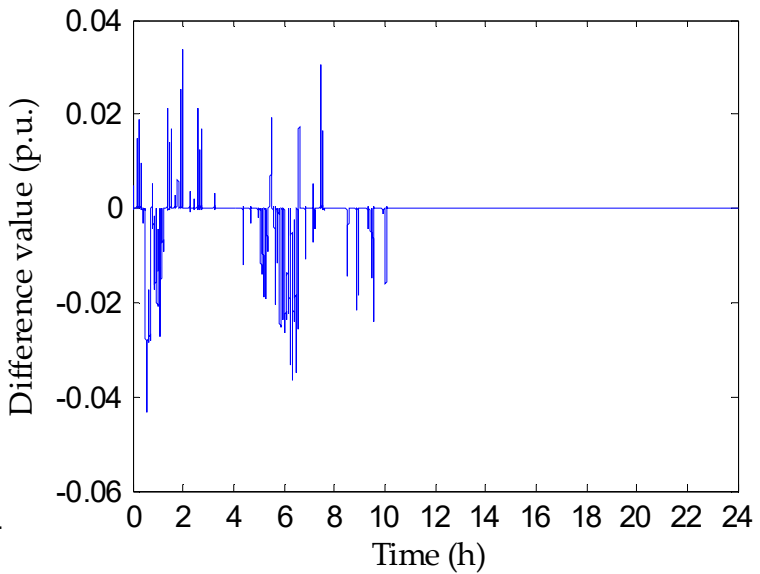

(d) Difference value of regulation power

Figure 12. Comparison of WTs participating in frequency regulation under the different control strategies $(d=0.05)$. (a) Frequency difference comparison between rotor speed control and coordinated control; (b) Difference value of frequency decreased by coordination control over rotor speed control; (c) Regulation power of wind farm comparison between rotor speed control and coordinated control;

(d) Difference value of wind farm regulation power increased by coordinated control over rotor speed control.

\subsubsection{Frequency Regulation Effects under Rotor Speed and Pitch Coordinated Control Strategy}

When $d=0.05$, under the rotor speed and pitch coordinated control strategy, the simulation results of the WTs participating in frequency regulation are shown in Figure 13.

As shown in Figure 13 and Table 3: $\overline{\Delta f}$ is $0.0283 \mathrm{~Hz}$, which is $9.58 \%$ lower than that of WTs non-participating in frequency regulation. $\overline{\Delta P_{W}}$ is 0.0096 p.u., which is $23.47 \%$ of the average wind farm power, and the average pitch angle action degree $\bar{\beta}$ is $0.0344^{\circ}$.

The data in Table 3 shows that as the reservation coefficient increases from $d=0.05$ to $d=0.1, \overline{\Delta f}$ decreases by $7.07 \%, \overline{\Delta P_{W}}$ increases by $6.95 \%$, and $\bar{\beta}$ increases by five times. Therefore, when designing the power reservation coefficient, the frequency regulation effects and the mechanical damage caused by the pitch angle action should be considered. 


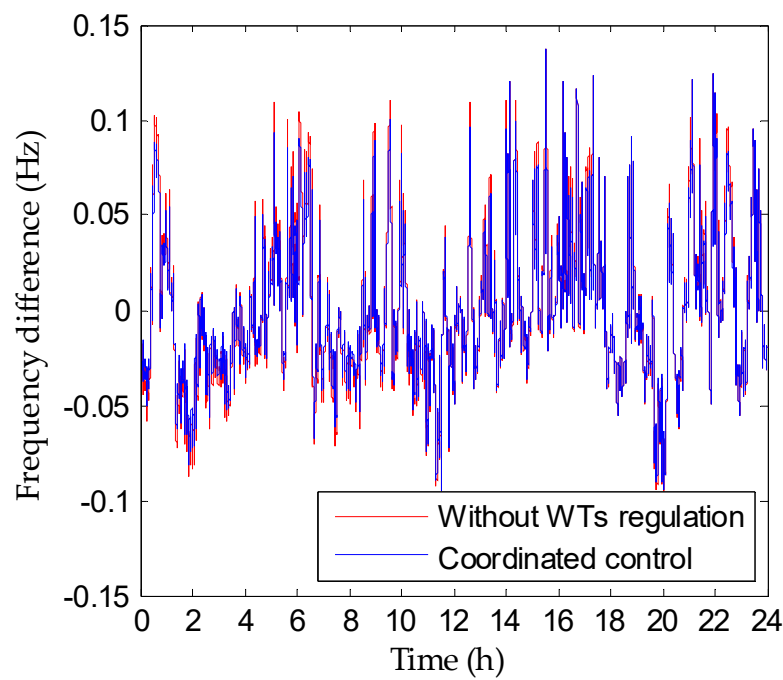

(a) Comparison of frequency difference

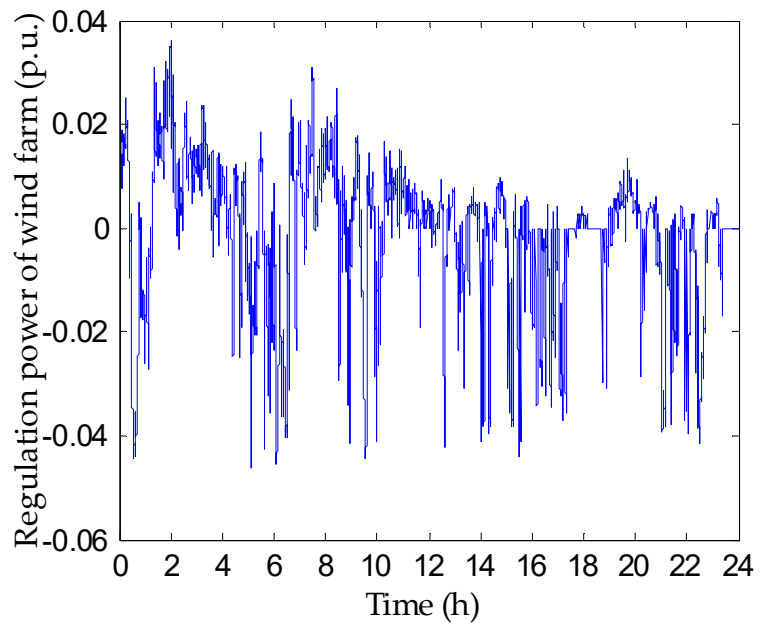

(c) Frequency regulation power of wind farm

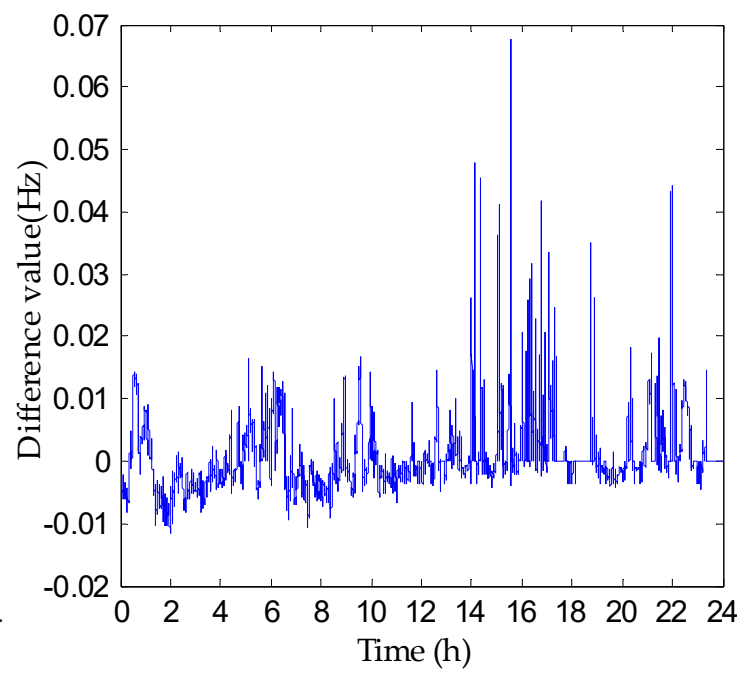

(b) Frequency decrease under coordinated control

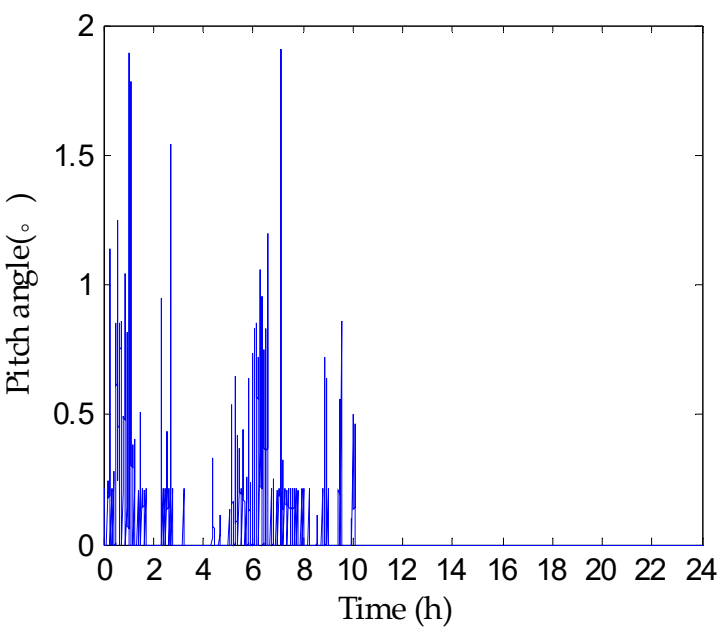

(d) Pitch angle of the WT

Figure 13. Simulation results under the coordinated control strategy $(d=0.05)$. (a) Frequency difference comparison between coordinated control and WTs not participating in frequency regulation; (b) Difference value of frequency decreased by coordinated control over WTs non-participating in frequency regulation; (c) Regulation power of wind farm; (d) Pitch angle of WT.

\subsection{Analysis of Wind Power Utilization under Different Control Strategies}

The WTs abandon the maximum power capture to participate in the bidirectional frequency regulation of the system. Because of the randomness of wind power and the system's frequency, it is inevitable that reservation power is used less or even zero, and the WTs participate in downward frequency regulation, which result in the wind curtailment phenomenon.

The WTs participate in frequency regulation, the wind power utilization under different control strategies are shown in the Table 4 . Compared with the rotor speed control strategy $d=0.05$, under the coordinated control strategy, when $d=0.05$ and $d=0.1$, the reservation power utilization decreases by $7.37 \%$ and $45.47 \%$, respectively, and the wind curtailment power increases by $27.9 \%$ and $100.5 \%$, respectively. 
Table 4. Comparison of wind power utilization under different control strategies.

\begin{tabular}{cccc}
\hline Parameter & $\begin{array}{c}\boldsymbol{d}=\mathbf{0 . 0 5} \\
\text { Speed Control }\end{array}$ & $\begin{array}{c}\boldsymbol{d = 0 . 0 5} \\
\text { Coordinated Control }\end{array}$ & $\begin{array}{c}\boldsymbol{d = 0 . 1} \\
\text { Coordinated Control }\end{array}$ \\
\hline Reservation power utilization (\%) & $38.93 \%$ & $36.06 \%$ & $21.23 \%$ \\
Average wind curtailment power (MW) & 1.0052 & 1.2857 & 2.3657 \\
\hline
\end{tabular}

Based on the above analysis, under the designed example of this paper, considering the dual target optimization of frequency quality and wind curtailment power, power reservation coefficient $d=0.05$ is more reasonable for WTs participating in the frequency regulation.

\section{Conclusions}

With different wind speeds, DFIGs can reserve a part of power and participate in the bidirectional frequency regulation under the rotor speed and pitch coordinated control. In the long term continuous frequency disturbance process, WTs participating in primary frequency regulation of the system effectively improves the frequency quality, and draw the following conclusions:

(1) We reveal the bidirectional regulation power constraints of the DFIG participating in frequency regulation: the regulation power under rotor speed regulation is restricted by the rated rotor speed, and the regulation power under pitch regulation is restricted by the time scale of the pitch action. While reserving a part of power to obtain available upward regulation power, the available downward regulation power is compressed.

(2) The effects of the bidirectional regulation power constraints on DFIGs participating in continuous frequency regulation are studied. When some wind speed-frequency difference events occur, the WT does not have the ability to provide the regulation power according to the setting adjustment coefficient, which leads to the degradation of frequency regulation effects and the increase of actual adjustment coefficient.

(3) The simulation results show that under the rotor speed and pitch coordinated control strategy, as the increase of the reservation coefficient, the regulation power of the wind farm increases, and the system frequency difference decreases, at the same time, the pitch angle action increases. Therefore, when designing the power reservation coefficient, the frequency regulation effects and the mechanical damage caused by the pitch angle action should be considered.

(4) WTs participating in frequency regulation improves the frequency quality of the system, at the same time, the phenomenon of wind curtailment inevitably occurs. A reasonable power reservation coefficient can achieve the dual optimization of improving frequency quality and reducing wind curtailment. In the example system of this paper, it is reasonable that the reserve coefficient is equal to 0.05 .

(5) In this paper, the capability and effects of DFIGs participating in long-term continuous frequency regulation are analyzed theoretically. The simulation results are obtained with the initial conditions of the wind speed and equivalent load fluctuation of the designed example. The application of practical engineering needs further improvement.

Author Contributions: T.C. and S.L. conceived of the theory and built the model. T.C. performed the experiments and analyzed the data. G.Y. and H.L. direct the writing of the paper. T.C. and S.L. wrote the paper.

Funding: This research was funded by the National Natural Science Foundation of China under Grant Number U1766204, and was funded by the National Key Research and Development Program of China under Grant Number 2017YFB0902004.

Conflicts of Interest: The authors declare no conflict of interest. 


\section{Nomenclature}

$P_{\mathrm{m}} \quad$ Mechanical power of wind turbine

$\rho \quad$ Air density

$S \quad$ Rotor sweep area

$v \quad$ Wind speed

$C_{\mathrm{P}} \quad$ Wind energy utilization coefficient

$\lambda \quad$ Tip speed ratio

$\beta \quad$ Pitch angle

$\lambda_{\mathrm{i}} \quad$ Intermediate variables

$c_{1} \sim c_{8} \quad$ Polynomial coefficient

$\omega_{\mathrm{r}} \quad$ Angular frequency of wind turbine

$R \quad$ Radius of wind turbine

d Power reservation coefficient of wind turbine

$P_{\text {Wopt }}(v) \quad$ Maximum captured power at the wind speed $v$

$\omega_{\mathrm{N}} \quad$ Rated rotor speed

$P_{\text {Wre }}(v) \quad$ Initial operation power at the wind speed $v$

$P_{\text {Wrtn }}(v) \quad$ Wind power at rated rotor speed

$\Delta P_{\text {Wrer }}(v) \quad$ Reservation power under rotor speed regulation at wind speed $v$

$\Delta P_{\text {Wrep }}(v) \quad$ Reservation power under $r$ regulation at wind speed $v$

$\Delta P_{\text {Wfr }}(v) \quad$ Regulation power under rotor speed regulation at wind speed $v$

$C_{\text {pmax }} \quad$ Wind energy utilization coefficient of MPPT

$C_{\mathrm{pr}} \quad$ Wind energy utilization coefficient after rotor speed regulation

$\Delta P_{\mathrm{os}}(v) \quad$ Maximum regulation power under rotor speed regulation

$\Delta P_{\text {Wup }}(v) \quad$ Available upward regulation power under rotor speed regulation

$\overline{\Delta P_{\mathrm{W}}} \quad$ Average of wind farm regulation power absolute

$\bar{\beta} \quad$ Average pitch angle

$\Delta P_{\mathrm{Wdn}}(v) \quad$ Available downward regulation power under rotor speed regulation

$\Delta P_{\text {wfp }}(v) \quad$ Regulation power under pitch regulation at wind speed $v$

$C_{\mathrm{pp}} \quad$ Wind energy utilization coefficient after rotor speed and pitch regulation

$\sigma_{\mathrm{G}} \quad$ Adjustment coefficient of synchronous generator

$\Delta f \quad$ Frequency difference of the system

$\Delta f^{*} \quad$ Per-unit value of $\Delta f$

$f_{\mathrm{N}} \quad$ Rated frequency of the system.

$P_{\mathrm{GN}} \quad$ Rated power of synchronous generator

$\Delta P_{\mathrm{G}} \quad$ Regulation power when the frequency difference is $\Delta f$

$\Delta P_{\mathrm{G}}^{*} \quad$ Per-unit value of $\Delta P_{\mathrm{G}}$.

$P_{\mathrm{WN}} \quad$ Rated power of wind turbine

$\Delta P_{\mathrm{W}} \quad$ Regulation power of wind turbine when frequency difference is $\Delta f$

$\Delta P_{\mathrm{W}}^{*} \quad$ Per-unit value of $\Delta P_{\mathrm{W}}$

$\Delta f_{\mathrm{dn}, \min }(v) \quad$ Lower limit of the frequency difference range

$\Delta f_{\text {up,max }}(v) \quad$ Upper limit of the frequency difference range

$\Delta P_{\text {Win }} \quad$ Regulation power of wind turbine distributed by the setting adjustment coefficient

$K_{\mathrm{W}} \quad$ Frequency characteristic coefficient of wind turbine

$\omega_{\max }, \omega_{\min } \quad$ Rotor speed limits

$T_{S} \quad$ Delay of pitch servo drive system.

$\frac{d \beta}{d t} \max ^{\prime} \frac{d \beta}{d t} \min$ Pitch rate limits

$\beta_{\max }, \beta_{\min } \quad$ Pitch amplitude limits

$\bar{d} \quad$ Average power reservation coefficient

$\overline{\Delta f} \quad$ Average of frequency difference absolute

$\overline{\sigma_{\mathrm{W}}} \quad$ Average adjustment coefficient of wind turbine 


\section{References}

1. Global Wind Energy Council. Global Wind Report. Available online: http://files.gwec.net/files/GWR2017. pdf (accessed on 25 April 2018).

2. Luo, X.; Wang, J.; Wojcik, J.D.; Wang, J.; Li, D.; Draganescu, M.; Li, Y.; Miao, S. Review of Voltage and Frequency Grid Code Specifications for Electrical Energy Storage Applications. Energies 2018, 11, 1070. [CrossRef]

3. Naderi, S.B.; Davari, P.; Zhou, D.; Negnevitsky, M.; Blaabjerg, F. A Review on Fault Current Limiting Devices to Enhance the Fault Ride-Through Capability of the Doubly-Fed Induction Generator Based Wind Turbine. Appl. Sci. 2018, 8, 2059. [CrossRef]

4. Rini Ann Jerin, A.; Kaliannan, P.; Subramaniam, U.; Shawky El Moursi, M. Review on FRT solutions for improving transient stability in DFIG-WTs. IET Renew. Power Gener. 2018, 12, 1786-1799. [CrossRef]

5. Yan, X.; Song, Z.; Xu, Y.; Sun, Y.; Wang, Z.; Sun, X. Study of Inertia and Damping Characteristics of Doubly Fed Induction Generators and Improved Additional Frequency Control Strategy. Energies 2019, 12, 38. [CrossRef]

6. Fan, G.; Liu, J.; Meng, H.; Wang, K. Primary Frequency Control Strategy for Wind Farms Under Output-Restricted Condition. Power Syst. Technol. 2016, 40, 2030-2037.

7. Tian, X.; Wang, W.; Chi, Y. Variable Parameter Virtual Inertia Control Based on Effective Energy Storage of DFIG-based Wind Turbines. Autom. Electr. Power Syst. 2015, 39, $20-26$.

8. Xiong, L.; Li, Y.; Zhu, Y.; Yang, P.; Xu, Z. Coordinated control schemes of super-capacitor and kinetic energy of DFIG for system frequency support. Energies 2017, 11, 103. [CrossRef]

9. Tang, Y.; Dai, J.; Ning, J.; Dang, J.; Li, Y.; Tian, X. An extended system frequency response model considering wind power participation in frequency regulation. Energies 2017, 10, 1797. [CrossRef]

10. Liu, B.; Yang, J.; Liao, K.; He, Z. Improved Frequency Control Strategy For DFIG-based Wind Turbines Based on Rotor Kinetic Energy Control. Autom. Electr. Power Syst. 2016, 40, 17-22.

11. Li, S.; Huang, Y.; Wang, L.; Lei, X.L.; Tang, H.Y.; Deng, C.J. Modeling Primary Frequency Regulation Auxiliary Control System of Doubly Fed Induction Generator Based on Rotor Speed Control. Proc. CSEE 2017, 37, 7077-7086, 7422.

12. Ding, L.; Yin, S.; Wang, T. Integrated Frequency Control Strategy of DFIGs Based on Virtual Inertia and Over-Speed Control. Power Syst. Technol. 2015, 39, 2385-2391.

13. Xue, Y.; Tai, N. Review of contribution of frequency control through variable speed wind turbine. Renew. Energy 2011, 36, 1671-1677.

14. Zhang, G.; Yang, J.; Sun, F.; Ge, Y.; Xing, Z. Primary Frequency Regulation Strategy of DFIG Based on Virtual Inertia and Frequency Droop Control. Trans. China Electrotech. Soc. 2017, 32, 225-232.

15. Zheng, D.; Ouyang, J.; Xiong, X.; Xiao, C.; Li, M. A System Transient Stability Enhancement Control Method Using Doubly Fed Induction Generator Wind Turbine with Considering Its Power Constraints. Energies 2018, 11, 945. [CrossRef]

16. Elosegui, U.; Egana, I.; Ulazia, A.; Ibarra-Berastegi, G. Pitch Angle Misalignment Correction Based on Benchmarking and Laser Scanner Measurement in Wind Farms. Energies 2018, 11, 3357. [CrossRef]

17. Whitby, B.; Ugalde-Loo, C.E. Performance of pitch and stall regulated tidal stream turbines. IEEE Trans. Sustain. Energy 2014, 5, 64-72. [CrossRef]

18. Kerdphol, T.; Rahman, F.S.; Mitani, Y. Virtual Inertia Control Application to Enhance Frequency Stability of Interconnected Power Systems with High Renewable Energy Penetration. Energies 2018, 11, 981. [CrossRef]

19. Zhao, J.; Gao, W.; Shangguan, M.; Zha, X.; Yue, S.; Liu, Y. Review on frequency regulation technology of power grid by wind farm. Power Syst. Prot. Control 2017, 45, 157-169.

20. Li, Y.; Xu, Z.; Wong, K.P. Advanced control strategies of PMSG-based wind turbines for system inertia support. IEEE Trans. Power Syst. 2017, 32, 3027-3037. [CrossRef]

21. Wu, Z.; Gao, W.; Wang, J.; Gu, S. A coordinated primary frequency regulation from permanent magnet synchronous wind turbine generation. In Proceedings of the 2012 IEEE in Power Electronics and Machines in Wind Applications (PEMWA), Denver, CO, USA, 16-18 July 2012; pp. 1-6.

22. Chaaban, R.; Ginsberg, D.; Fritzen, C.P. Structural Load Analysis of Floating Wind Turbines Under Blade Pitch System Faults. In Wind Turbine Control and Monitoring; Luo, N., Vidal, Y., Acho, L., Eds.; Springer: Zürich, Switzerland, 2014; pp. 301-334. 
23. Merabet, A.; Keeble, R.; Rajasekaran, V.; Beguenane, R.; Ibrahim, H.; Thongam, J.S. Power Management System for Load Banks Supplied by Pitch Controlled Wind Turbine System. Appl. Sci. 2012, 2, 801-815. [CrossRef]

24. Dileep, G.; Singh, S.N. Maximum Power Point Tracking of Solar Photovoltaic System Using Modified Perturbation and Observation Method. Renew. Sustain. Energy Rev. 2015, 50, 109-129. [CrossRef]

25. Wang, J.; Lu, S.; He, X.; Xia, J. Study on parameters matching of rotor power coefficient for large scale wind turbine. Acta Energiae Solaris Sin. 2012, 33, 221-225.

26. Ghefiri, K.; Bouallègue, S.; Garrido, I.; Garrido, A.J.; Haggège, J. Complementary Power Control for Doubly Fed Induction Generator-Based Tidal Stream Turbine Generation Plants. Energies 2017, 10, 862. [CrossRef]

27. Ghefiri, K.; Bouallègue, S.; Haggège, J. Modeling and SIL simulation of a Tidal Stream device for marine energy conversion. In Proceedings of the 2015 6th International Renewable Energy Congress (IREC), Sousse, Tunisia, 24-26 March 2015; pp. 1-6.

28. He, K.; Qi, L.; Zheng, L.; Chen, Y. Combined Pitch and Trailing Edge Flap Control for Load Mitigation of Wind Turbines. Energies 2018, 11, 2519. [CrossRef]

29. Bevrani, H. Robust Power System Frequency Control; Springer: New York, NY, USA, 2014.

30. Kundur, P. Power System Stability and Control; McGraw-Hill: New York, NY, USA, 1994.

31. Pahasa, J.; Ngamroo, I. Coordinated control of wind turbine blade pitch angle and PHEVs using MPCs for load frequency control of microgrid. IEEE Syst. J. 2016, 10, 97-105. [CrossRef]

32. Zhou, Q.; Wang, N.; He, S.; Shen, C.Y.; Yang, L.; Zhao, L.; Chen, Z. Summary and Prospect of China's New Energy Development under the Background of High Abandoned New Energy power. Power Syst. Prot. Control 2017, 45, 146-154.

(C) 2019 by the authors. Licensee MDPI, Basel, Switzerland. This article is an open access article distributed under the terms and conditions of the Creative Commons Attribution (CC BY) license (http:/ / creativecommons.org/licenses/by/4.0/). 